\title{
PEDAGOGIAS DO SOCIAL E DO AFETIVO \\ EM "CAPÍTULO DOS CHAPÉUS", DE MACHADO DE ASSIS
}

\section{RAFAEL MEIRE}

Pontifícia Universidade Católica do Rio de Janeiro Rio de Janeiro, Rio de Janeiro, Brasil

Resumo: Este artigo discute algumas tendências críticas seminais em torno da prosa machadiana, notadamente aquelas que trabalham com o conceito de sociedade enquanto categoria sociológica sumária. Para tanto, analisa aspectos do conto "Capítulo dos chapéus", aproximando-os das propostas teóricas do antropólogo Bruno Latour (2012) acerca da noção de social. Em diálogo com essas propostas, são levantadas hipóteses sobre o estatuto ontológico dos objetos e sua relação com as políticas afetivas do século XIX.

Palavras-chave: Sociedade; Social; Objetos; Subjetividades.

\section{SOCIAL AND AFFECTIVE PEDAGOGIES \\ IN "A CHAPTER OF HATS," BY MACHADO DE ASSIS}

\begin{abstract}
This article approaches some seminal critical trends involving the prose of Machado de Assis, notably those that address the concept of society as a mere sociological category. Therefore, this study analyzes aspects of the short story, "A Chapter of Hats," by approaching the theoretical proposals put forth by anthropologist Bruno Latour (2012) about the notion of the social. In dialogue with these proposals, hypotheses are raised regarding the ontological statute of objects and their relation to the affective policies of the nineteenth century.
\end{abstract}

Keywords: Society; Social; Objects; Subjectivities. 
apazes de situar ou, ao contrário, deixar dessituados personagens humanos, parece-nos que os objetos e as coisas ditas inanimadas, como a rua, a casa, o consultório do dentista, as lojas, as vestimentas das pessoas etc. possuem certo protagonismo no conto machadiano "Capítulo dos chapéus", publicado em 1884 na coletânea Histórias sem data. Em certa medida, esse protagonismo diz respeito àquilo que Alfredo Bosi (2007), em seu ensaio "A máscara e a fenda", chama de segunda natureza: a incidência da exterioridade da vida social na interioridade subjetiva dos personagens, possuindo aquela tanta importância quanto esta última no que diz respeito à sua psicologia.

A fim de problematizar alguns pressupostos teóricos que, alicerçados no conceito de sociedade, sustentam a noção de segunda natureza - a eles propondo caminhos alternativos -, tomo como ponto de partida a teoria que o personagem Conrado, em "Capítulo dos chapéus", expõe à sua esposa, Mariana, e que se expressa nos seguintes termos:

- A escolha do chapéu não é uma ação indiferente, como você pode supor; é regida por um princípio metafísico. Não cuide que quem compra um chapéu exerce uma ação voluntária e livre; a verdade é que obedece a um determinismo obscuro. A ilusão da liberdade existe arraigada nos compradores, e é mantida pelos chapeleiros que, ao verem um freguês ensaiar trinta ou quarenta chapéus, e sair sem comprar nenhum, imaginam que ele está procurando livremente uma combinação elegante. O princípio metafísico é este: - o chapéu é a integração do homem, um prolongamento da cabeça [...]. Quem sabe? Pode ser até que nem mesmo o chapéu seja complemento do homem, mas o homem, do chapéu... (ASSIS, 2008, p. 378)

Leiamos tal teoria de modo a dela destacar dois aspectos principais, aproveitando, de um lado, sua possível rentabilidade teórica, e discutindo aquilo que, de outro, em nosso entender, se apresenta como um problema de ordem política e epistemológica. Sublinhe-se que, em ambos os casos, o que está em jogo é a relação que buscaremos traçar entre a teoria de Conrado e algumas perspectivas críticas (que não se pretendem exaustivas) na seara dos estudos machadianos. Vamos, pois, ao primeiro aspecto a ser destacado.

Quando o personagem diz: "Não cuide que quem compra um chapéu exerce uma ação voluntária e livre; a verdade é que obedece a um determinismo obscuro", temos aí uma questão. Essa questão se dá a ver com nitidez na frase seguinte, segundo a qual "[a] ilusão da liberdade existe 
arraigada nos compradores, e é mantida pelos chapeleiros [...]" (ASSIS, 2008, p. 378).

O que nos interessa nas frases em questão é a condição na qual os compradores e os vendedores se veem encerrados: a de pessoas iludidas, ou seja, supostamente ignorantes em relação ao que no ato de se escolherem chapéus realmente se passa do ponto de vista da apreensão da realidade - ao mesmo tempo que elas, cegas nessa condição, julgam apenas se tratar da busca por combinações elegantes. Segundo essa perspectiva, quem saberia então o que de fato se passa? Conrado Seabra, cujas abstrações pairariam acima da ignorância de compradores e vendedores que, desprovidos de voz, ilustrariam exemplarmente sua teoria. Nesse caso específico, trata-se das elucubrações do marido de Mariana, mas, do ponto de vista de um modus operandi teórico, poderia se tratar das investigações de um cientista social, de um historiador ou de um crítico literário, como veremos a seguir.

Entre outros, esse é um dos problemas discutidos por Bruno Latour (2012) em Reagregando o social: uma introdução à teoria do ator-rede. Nesse trabalho, o autor questiona os pressupostos da sociologia tradicional, revisando suas categorias e investindo em outras possibilidades interpretativas. Para tanto, expõe-nos, como ponto de partida, duas intuições principais que se encontram nas origens da sociologia: a de que, quando começamos a agir, outras forças logo passam à ação; e a de que o mundo é feito de tantas e tais assimetrias e desigualdades que, diante da resistência que estas impõem à iniciativa individual, acredita-se que exista uma entidade específica - a sociedade - que se sobrepõe a quaisquer que sejam as atividades humanas.

Que outras forças passem à ação tão logo comecemos a agir (primeira intuição) é coisa que para Latour possui a maior importância, desde que estas não sejam tomadas de antemão como forças sociais e de que sejam observadas naquilo que possuem de mais vigoroso: sua capacidade de agrupar agentes provenientes de domínios heterogêneos, evidenciando sua porosidade em relação aos domínios do natural e do cultural, do animado e do inanimado, do moral e do tecnológico e assim por diante. Quanto à persistência, no mundo, de assimetrias e desigualdades, e à correlata existência de forças que as ultrapassariam (segunda intuição), o importante é não confundir estas com aquelas, isto é, usá-las como explicações sociais ali onde o necessário seria investigar seus próprios modos de funcionamento. Fazê-lo implicaria apenas repetir e prolongar tais assimetrias e 
desigualdades, além de supô-las inerentes a um mundo e a uma realidade que, segundo o autor, nesse caso se apresentam em sua imobilidade.

Para a sociologia tradicional, então, por trás de quaisquer atividades humanas e/ou fenômenos a serem observados, haveria sempre a presença de forças sociais que seriam capazes de explicá-los, situando-se como pano de fundo e definindo-se como uma "esfera específica da realidade" (LATOUR, 2012 , p. 20). Já para a teoria do ator-rede, a noção de social de modo algum pode ser tomada como se esta fosse uma substância, ou seja, como se ela correspondesse a um domínio autônomo a partir do qual seria possível se fornecerem explicações a um estado de coisas dado. Antes, o social seria da ordem de um movimento, de um fluido que ganha estabilidade, aqui e ali, a partir da articulação de meios materiais diversos, que deixam de figurar, por sua vez, como simples instrumentos através dos quais um quadro de referências é veiculado e passam a produzir teorias próprias - não cabendo ao estudioso nem "revelar aos atores o que eles são" e tampouco "acrescentar alguma lucidez à sua prática cega" (LATOUR, 2012, p. 31).

Note-se que, em comparação com a exposição de Conrado, temos uma outra paisagem teórica, segundo a qual falar em "ilusão", seja a de compradores ou chapeleiros, seja a de qualquer outro ator social, deixa de ser possível ou desejável. A fim de trazer essa discussão para o terreno da crítica literária, tomemos algumas tendências interpretativas acerca da obra de Machado de Assis, notadamente aquelas que, a partir de meados dos anos 1970, se consolidaram como referências fundamentais na seara da fortuna crítica machadiana. Em relação a essas tendências, o pensamento latouriano oferece contrapontos teóricos interessantes - mas de modo algum sumários, diga-se desde já. Antes, trata-se de uma maneira, entre outras, de se observar o fenômeno social.

Para tanto, partamos das perspectivas do crítico inglês John Gledson (2006) em estudo sobre "Capítulo dos chapéus". Neste, o autor propõe cruzamentos entre o conto de Machado e o romance Le mot de l'énigme, da escritora francesa Madame Craven. Esse romance, como se sabe, é um dos três livros que a personagem Mariana costumava ler com assiduidade. E foi pelo fato de ele ter tido mais releituras que os outros dois, por parte da moça, que Gledson apostou na ideia de que nessa obra haveria elementos pertinentes para que compreendêssemos melhor os sucessos de "Capítulo dos chapéus".

Le mot de l'énigme estrutura-se sob a égide de valores morais e religiosos, os quais, segundo o crítico inglês, fornecem elementos que 
explicam "o caráter de Mariana, que aparenta ser claro e previsível" (GLEDSON, 2006, p. 125). Neste ponto, John Gledson toca no aspecto chave de seu ensaio, que é propor uma leitura feminina de "Capítulo dos chapéus"; leitura essa que, como veremos, dialoga diretamente com as questões que sintetizamos em torno da crítica à noção totalizadora de sociedade ou de explicação social, via Bruno Latour.

Segundo a interpretação de Gledson, apenas relativamente é possível dizer que Mariana é acomodada, submissa e indiferente à situação de opressão em seu casamento com Conrado: as sucessivas releituras de Le mot de l'énigme seriam para a personagem uma maneira de transgressão, na medida em que lhe poriam em contato reiterado com essa história em que o adultério, aí presente como tema, se dá a ver como uma possibilidade para a mulher no contexto de casamentos infelizes. Para a personagem machadiana - como para a personagem de Craven -, entretanto, essa possibilidade se realiza apenas no âmbito da fabulação, da literatura: "O que Mariana quer experimentar uma e outra vez é a tentação de transgredir os limites de um casamento sem amor [...], junto com as sanções que impossibilitam qualquer movimento nesse sentido" (GLEDSON, 2006, p. 129).

Daí em diante, o crítico evidencia o quadro de referências que se impõe como limite histórico-sociológico para as suas leituras, a saber, a sociedade patriarcal na qual Mariana está inserida. Assim, ao dissertar sobre o caráter da personagem, propõe todo um sistema de substituições (LATOUR, 2012, p. 77-79) ${ }^{1}$ por meio do qual "apatia", "inércia" e "indiferença" são explicadas por expressões e frases como "ideologia religiosa da castidade", "contexto burguês" e "país em que, durante o Império, era proibido tomar o véu" (GLEDSON, 2006, p. 132).

Em sua minúcia no trato com detalhes dos textos, datas, referências e possibilidades interpretativas, o crítico inglês leva a vocação hermenêutica às últimas consequências e, fazendo-o, levanta hipóteses as mais diversas sobre o conto em questão. Entre tantas outras, uma dessas hipóteses diz respeito à teoria de Conrado sobre a qual vínhamos discorrendo anteriormente.

Sugere o ensaísta que Conrado não seria tão douto assim, e que a sua teoria não passa de "embustes sarcásticos cujo objetivo é apenas humilhar Mariana" (GLEDSON, 2006, p. 132). Já vimos que a leitura feminina de Gledson é algo limitadora, uma vez que não concede à personagem machadiana a possibilidade de escapar a um cotidiano predominantemente

\footnotetext{
1 Entre outras práticas analíticas, a substituição de termos, segundo o autor, possui papel de destaque nos métodos tradicionais de análise sociológica.
} 
masculino e opressor senão pelas vias da fabulação e da representação. Acrescente-se que essa leitura possui outro aspecto, qual seja, uma condescendência paternalista que, a rigor, é fruto da mesma lógica patriarcal que o crítico busca combater. Diz-nos o autor de Por um novo Machado de Assis:

[...] as leituras de Mariana podem ser de digestão fácil, mas pelo menos ela leu seus livros, e como! Sete, dez e onze vezes! E um deles está em francês - francês comum e fácil de ler, mas ainda assim... (GLEDSON, 2006, p. 128-129)

Eis-nos diante de um bom exemplo de como, por vezes, acontece a uma hermenêutica calcada em explicações sociais de prolongar e manter intactas as desigualdades e assimetrias que ela critica - conforme nos propõe Latour em Reagregando o social.

Colocamo-nos, portanto, na contramão do método históricosociológico de John Gledson. Isso não significa, absolutamente, que não levemos em consideração os problemas traçados por esse autor, ou por aqueles cujas visadas críticas, incontornáveis, contribuíram solidamente, ao longo da segunda metade do século XX, para o aprofundamento de um pensamento nacional que se quer maduro no que diz respeito ao problema da dependência cultural e suas consequências estéticas e políticas - como Raymundo Faoro, Alfredo Bosi, Roberto Schwarz, entre outros. Significa, apenas, que o conceito de sociedade - a nosso ver partilhado por todos, ainda que diferenças internas sejam apontadas pelos próprios autores ${ }^{2}$ - funciona menos como uma grande categoria explicativa do que como elemento exclusivamente humano que, ao lado de tantos outros (humanos e nãohumanos), concorre para a composição progressiva de um social fraturado.

Em certa medida, pode-se dizer que o aparato teórico-conceitual de autores como John Gledson, Alfredo Bosi ou Roberto Schwarz tende a, de um lado, tomar o humano e seus vínculos morais, legais e simbólicos (LATOUR, 2012, p. 116) como espaço privilegiado no seio do qual se desenvolve o pensamento crítico e, de outro, tomar os objetos técnicos e as

\footnotetext{
2 É o caso, por exemplo, da crítica de Alfredo Bosi (BOSI, 2006, p. 37) ao "olhar macrossociológico" (no qual se situam nomes como Astrojildo Pereira, Raymundo Faoro e Roberto Schwarz), quando esse olhar "subordina à situação local", de maneira totalizante, traços formais e existenciais de personagens e situações ficcionais; traços esses que para o crítico se justificam via referências outras, tais como a ficção de Laurence Sterne e Xavier de Maistre, no caso de Memórias póstumas de Brás Cubas, e dos estudos de Augusto Meyer, para ficarmos apenas com algumas dessas referências.
} 
coisas em geral como meios a partir dos quais se acessam esses vínculos tidos como referências fundamentais. Desse modo, se não é possível afirmar que os autores em questão possuem, todos, o mesmo pendor analítico, acreditamos não ser exagero propor que, em maior ou menor medida, todos eles tomam o conceito de sociedade como conceito operatório, sobretudo no que diz respeito à sua relação com valores predominantemente humanistas e modernos (LATOUR, 2013, p. 35-38). ${ }^{3}$

Além disso, pode-se dizer que tanto a verve hermenêutica quanto sua correlata prática de substituição de termos, que abordamos via John Gledson, se fazem sentir, embora menos acentuadas, em suas principais propostas teóricas. Particularmente sofisticada é a maneira como Roberto Schwarz (2000a; 2000b), por exemplo, as articula em sua interpretação da obra machadiana.

Vide, a esse respeito, o clássico Um mestre na periferia do capitalismo, em que expressões como "ideia grandiosa e útil", "ideia fixa" e "panaceia antihipocondríaca", relativas ao Emplasto Brás Cubas, são substituídas por termos como "ideário liberal-burguês", "filosofia do inconsciente", "medicina moderna" (SCHWARZ, 2000b, p. 32) e assim por diante. Do ponto de vista hermenêutico, contudo, de modo algum este é o ponto de chegada do crítico que, antes, esmiúça a maneira como esses termos são deslocados e esvaziados de seu sentido próprio nas Memórias póstumas.

Tal se dá, principalmente, porque a maneira volúvel com que Brás Cubas articula universalismo ilustrado e experiência local (sempre em prejuízo do primeiro) dá as medidas de um descompasso estrutural que, segundo o autor, é, entretanto, naturalizado pelas elites nacionais: a convivência entre ideias modernas e práticas coloniais no Brasil oitocentista; entre estas últimas, o sistema escravista e o clientelismo. Fator extraliterário, esse descompasso - trata-se das "ideias fora do lugar" (SCHWARZ, 2000a) seria mimetizado exemplarmente pela pena machadiana e, além de não se restringir a esse romance em particular (estendendo-se, ao contrário, por toda a obra do autor fluminense), se apresenta como poderoso diagnóstico sociológico, na medida em que rastrearia as forças sociais que praticamente imobilizam a sociedade brasileira.

\footnotetext{
3 Nesta obra (LATOUR, 2013), o antropólogo examina a dinâmica do mundo moderno, que consistiria, de um lado, na imposição de fraturas rígidas - onde se situa o humanismo - entre os domínios do fato (natureza), do poder (sociedade) e do discurso (referência) e, de outro, na liberação permanente de processos de hibridização entre esses domínios.
} 
Em suma, ora de maneira decisiva, ora lateralmente, o social, substancializado e abordado de modo a dar relevo aos vínculos humanos em detrimento de outros modos de vida, costuma impor-se como limite relativo para essa tradição crítica, ainda que, em meio às diferenças de abordagem que as marcam, haja espaço para problematizações das investidas decididamente sociológicas (cf. nota 2).

Talvez não seja por outro motivo que John Gledson não leve a sério o conteúdo da teoria de Conrado, desqualificando-a ali onde esta propõe ideias, inusitadas, que resistem às investidas de explicações sociais. Quer nos parecer que é por esse mesmo motivo que em $O$ enigma do olhar Alfredo Bosi nos propõe:

Vejo nos contos maduros de Machado, escritos depois de franqueada a casa dos quarenta anos, o risco em arabesco de "teorias", bizarras e paradoxais teorias, que, afinal, revelam o sentido das relações sociais mais comuns e atingem alguma coisa como a estrutura profunda das instituições. (BOSI, 2007, p. 85)

De fato, se o primeiro aspecto da teoria do bacharel não apresenta problemas nesse sentido, o mesmo não se pode dizer em relação ao segundo, o qual destacamos a partir de agora, e onde se lê que

[o] chapéu é a integração do homem, um prolongamento da cabeça, um complemento decretado $a b$ eterno; ninguém o pode trocar sem mutilação [...]. Quem sabe? Pode ser até que nem mesmo o chapéu seja complemento do homem, mas o homem, do chapéu... (ASSIS, 2008, p. 378)

Caso levemos em conta as preocupações gerais de $O$ enigma do olhar e, mais especificamente, do ensaio "A máscara e a fenda" (BOSI, 2007), perceberemos que alguns vetores desempenham papel privilegiado no âmbito de suas argumentações. Entre eles, destaquem-se o status social dos personagens em geral e sua contraparte imediata, a saber, as situações de desigualdade e assimetria (também sociais) entre esses personagens. Para o ensaísta, essa tensão atravessa grande parcela dos contos de Machado - dos primeiros aos últimos que o escritor publicou em vida. Grosso modo, a diferença entre estes e aqueles residiria na solução dada pelo contista para que as tensões entre status e desigualdade encontrassem uma formulação ficcional na qual o interesse e o cálculo não fossem tomados, de antemão, como gestos moralmente condenáveis. 
Essa solução ficcional consiste na composição necessária da máscara. A partir daí, o espaço antes ocupado por tipologias dicotômicas entre personagens bons e maus, bem e mal-intencionados, cede lugar ao mundo complexo e ambíguo da psicologia humana - quinhão realista do escritor fluminense. Nesse contexto, parecer e ser, aparência e essência tornam-se palavras equivalentes, ao mesmo tempo que ganha relevo, conforme propusemos ao início do presente ensaio, a segunda natureza desses personagens, a qual consistiria, precisamente, no "status, [n] a sociedade que se incrusta na vida" (BOSI, 2007, p. 81).

Daí em diante, passa-se de um estado de coisas que se limitava às histórias de suspeita e engano a outro em que o mundo da Aparência dominante (BOSI, 2007, p. 84) não só ganha relevo como se apresenta como dado determinante. Segundo essas novas regras, o sujeito não encontra realização possível senão em meio social, ou, para ser mais exato, em meio às instituições às quais esse sujeito deve se agarrar, já que são nestas que "se obrigam e se satisfazem as necessidades básicas dos grupos humanos" (BOSI, 2007, p. 81). Fora daí - propõe-nos o crítico -, só haveria loucura, disparate e naufrágio existencial. Note-se, portanto, que mesmo no caso de Bosi, que se coloca na contramão de perspectivas estritamente sociológicas, o recurso ao social enquanto força de atração totalizante não deixa de possuir protagonismo - muito pelo contrário. ${ }^{4}$

No âmbito da presente reflexão, o interesse pelo "Capítulo dos chapéus" se dá pelo fato de, aí, o mundo da Aparência dominante e da segunda natureza ser bastante presente. Em que pesem as excelentes análises críticas de Alfredo Bosi, por trás desse mundo de modo algum enxergamos a "estrutura profunda das instituições" (BOSI, 2007, p. 85). A nosso ver, é como se num conto que dramatiza aparências em sua plasticidade e uma teoria que foge ao senso comum, uma e outra coisa precisassem ser pensadas de modo que sua articulação seja examinada com vistas a rastrear o funcionamento das subjetividades no âmbito de um campo de forças (KLINGER, 2014, p. $75) .5$

\footnotetext{
4 Notemos, por exemplo, a seguinte observação de Bosi (2007, p. 100) a respeito do conto "O espelho". Segundo o autor, este "faria as delícias de um contemporâneo de Machado, o sociólogo francês Émile Durkheim, e de todos os que identificam o eu com a sua função". Ora, são precisamente as bases teóricas formuladas por Durkheim (2007), pai da sociologia, que Bruno Latour (2012) questiona em Reagregando o social, ao mesmo tempo que propõe perspectivas alternativas - as quais endossamos no presente ensaio - acerca dos fatos sociais.

5 Neste trabalho, a autora (KLINGER, 2014) discute os termos de uma possível "virada afetiva" nos estudos de literatura, buscando redefinir os desafios do estético, suas dimensões éticas e políticas, em relações de aproximação e afastamento com os legados da modernidade.
} 
Ao propor que "o chapéu é a integração do homem, um prolongamento da cabeça" (ASSIS, 2008, p. 378), a teoria de Conrado desafia elos apenas instrumentais entre sujeitos e objetos. Fazendo-o, ela levanta dúvidas quanto ao pressuposto (moral) segundo o qual a não-humanos só estaria reservada a condição de corpos objetificados, desprovidos de agência e hierarquicamente inferiores aos humanos propriamente ditos. Vejamos em que sentido isso se dá em "Capítulo dos chapéus". Antes, contudo, tragamos dois conceitos seminais de Bruno Latour (2012) para a discussão empreendida em Reagregando o social.

Em sua tentativa de liberar as forças do adjetivo social ("forças sociais"), o autor nos propõe duas formas de pensar os atores sociais: enquanto intermediários ou enquanto mediadores (LATOUR, 2006, p. 113123). No primeiro caso, forças sociais atravessariam esses atores sem que estes sofressem qualquer tipo de transformação, ao mesmo tempo que a eles - meros "informantes" humanos - caberia ilustrar a existência efetiva de tais forças a incidirem tanto sobre si e suas ações (em geral, sem que tenham consciência disso), quanto sobre a sociedade na qual estão inseridos.

Já no segundo caso, o que há são forças em relação, as quais, associando-se a sujeitos e objetos, entendidos como mediadores, necessariamente produzem e sofrem transformações. Segundo essa orientação, transportar é sempre transformar (LATOUR, 2006, p. 58). Nesse caso, o social se comporia e se decomporia mediante (re)associações constantes. Ao mesmo tempo, a gama de atores a concorrerem para isso se alarga, fazendo com que a ação, antes limitada a sujeitos intencionais, se redistribua, estendendo-se a objetos técnicos e meios materiais - que passam a ser considerados, como aqueles, atores sociais relevantes.

Se observarmos o enredo narrativo do conto machadiano em questão e a forte influência que os estímulos do mundo exterior exercem sobre o espírito da personagem Mariana, perceberemos que esses estímulos estão longe de operar como elementos ficcionais secundários frente ao que seria o essencial da narrativa: as relações de poder próprias à lógica patriarcal, no seio da qual Conrado, com sua excêntrica teoria, subjuga a protagonista.

Sem desconsiderar essa importante coordenada sociológica, diríamos, antes, que o aspecto nodal de "Capítulo dos chapéus" é a capacidade que tais estímulos possuem de transformar o despeito inicial de Mariana, assentando-o sobre outras bases. Lembremos que o conto se inicia com a moça profundamente ressentida e se encerra com uma mudança de perspectiva por parte da personagem que, a certa altura, se pergunta: "mas 
era caso de doer-se tanto? Era razoável o espalhafato?" (ASSIS, 2008, p. 384). Que aconteceu? - indagamo-nos de nossa parte.

O que se passa é que "Capítulo dos chapéus" nos traz dois modos distintos de aproximação com o mundo exterior. Para lançarmos mão da terminologia de Latour, diríamos que o primeiro modo apresenta os objetos e as coisas em geral como simples intermediários. É quando as relações materiais respondem a funções meramente instrumentais, não causando maiores abalos ou desvios nas expectativas e nos cursos de ação dos personagens, em especial de Mariana: trata-se da inadequação, no entender da moça, do chapéu baixo de Conrado às suas funções sociais de advogado grave; da organização de móveis e cortinas a refletirem a uniformidade dos hábitos da moça; da própria casa, "tão quieta, com todas as cousas nos seus lugares" (ASSIS, 2008, p. 383-384), em consonância com suas características morais etc. Em outras palavras, teríamos aqui toda uma lógica em que o exterior inflaciona a interioridade subjetiva da personagem.

O segundo modo, por sua vez, nos apresenta objetos e coisas como mediadores. Nesse caso, estes jamais operam segundo horizontes de expectativa predefinidos, e tampouco como matéria inerte através da qual ações, quaisquer que sejam, sejam apenas transportadas. Conforme vimos, um mediador sempre altera um curso de ação dado, transformando-o tão logo este último entre em contato com ele. É o que se dá com Mariana, a cada vez, em seu passeio com Sofia pela rua do Ouvidor, em que o contato com estímulos vários a leva, ao fim e ao cabo, a se comprazer com aquilo que, momentos antes, a incomodava: o chapéu baixo do marido - mesmo que tal se dê, segundo um gesto defensivo, pelo fato de o chapéu ser aquele conhecido "de longos anos" (ASSIS, 2008, p. 385).

Ao reconciliar-se com Conrado, teria a personagem sucumbido de maneira desavisada à força alienante das coerções sociais que, entretanto, ao início da narrativa ela havia enxergado tão bem? Não é o que nos parece. Diríamos, ao contrário, que as associações feitas entre Mariana e a cadeia de mediadores pela qual ela passa lhe permitem fazer uma espécie de operação subtrativa, deduzindo da lógica patriarcal os termos de uma ética própria; a qual, se não elimina as pressões dessa lógica sobre si, certamente as desloca, encontra em relação a elas uma saída criativa (DELEUZE, 2014, p. 15).

Neste particular, esse conto de Machado se aproxima dos termos daquilo que os filósofos Gilles Deleuze e Félix Guattari (2014) teorizariam mais de meio século depois: a articulação do dado individual ao imediato político - uma das características de seu conceito de literatura menor 
(DELEUZE; GUATTARI, 2014, p. 36). Para os autores, mais do que propor críticas sociais a se darem via regime mimético, de modo que essas críticas mobilizem grandes conjuntos molares (aos quais Latour chamaria, por seu turno, de forças sociais), a literatura seria capaz de desarticular "agenciamentos maquínicos" (DELEUZE; GUATTARI, 2014, p. 89). Esses agenciamentos seriam sempre investimentos de um campo social, a se darem concomitantemente em níveis micro e macropolítico, individual e coletivo (DELEUZE; GUATTARI, 2014, p. 86-90). ${ }^{6}$ A bem dizer, para além da fratura ontológica entre os planos do sujeito e do objeto, o que está em jogo, nesse contexto, é uma aposta na liberação das forças que os atravessam (que, como na proposta latouriana, se desvencilham de predicados fixados e hierarquizados de antemão) e na redistribuição das agências entre um e outro.

É nesse sentido que acreditamos que "Capítulo dos chapéus" nos oferece uma pedagogia do social e do afetivo: ao expor duas maneiras distintas de se lidar com as relações materiais e encaminhando seu enredo de modo que se arme uma tensão entre ambas, o conto redimensiona o alcance político da experiência; no caso, a experiência afetiva de Mariana, cuja capacidade de intervir nos modos de vida de que faz parte se torna, então, possível. Essa possibilidade é da ordem daquilo que Latour (1999, p. 32) chama de "composição progressiva do mundo comum", expressão que, escapando a categorias sumárias, busca redefinir o conceito de política, bem como o que se espera desta última enquanto práxis arredia a concepções duais acerca da subjetividade. Observado a partir desse ponto de vista, "Capítulo dos chapéus", a nosso ver, antecipa questões que só encontrariam formulações teóricas efetivas (ao lado das propostas histórico-sociológicas descritas anteriormente) a partir dos anos 1970.

Em estudo que, entre outras coisas, traça relações entre literatura e doença, Roberto Corrêa dos Santos (1999) relembra aqueles personagens que, presentes em Flaubert e Machado, sabem fazer saudável uso das máscaras como artifício para lidar com o mundo exterior, qualificando-os como "escritores de rostos" (SANTOS, 1999, p. 24). Abundantes na prosa oitocentista, esses personagens se mostrariam sensíveis às políticas afetivas da série histórica a que pertencem - momento em que, segundo o autor, a

6 Neste trabalho, entre outros aspectos, a questão teórica das relações entre crítica social e representação, em literatura, é problematizada de maneira bastante pormenorizada pelos autores (DELEUZE; GUATTARI, 2014). Desdobrar de maneira mais detida os conceitos aí apresentados é coisa que escapa aos limites e propostas deste artigo, configurando-se como tarefa, portanto, a ser realizada em trabalhos futuros. 
fragmentação da unidade burguesa frente à multiplicidade do fora anda lado a lado com a inexistência de saberes psíquicos sistematizados a proporem cadeias de mediações entre sujeitos, objetos e a própria linguagem enquanto domínio passível de exame (coisa que mudaria sensivelmente na arte e na literatura do século XX).

Para Santos, contudo, esses rostos que se escrevem não são apenas aqueles que, valendo-se de tais máscaras, performam falseamentos enquanto estratégia de autoproteção (como a personagem Sofia e, à certa altura de "Capítulo dos chapéus", a própria Mariana), única alternativa para que se possa transitar, evitar danos e, no limite, sobreviver em meio às instituições sociais. Inscritos neste ou naquele personagem em particular, tais rostos, mais amplamente, são também aqueles que se singularizam através dos "variados artifícios críticos de um estilo" (SANTOS, 2008, p. 138).

Como já nos propôs Haroldo de Campos (2006) acerca do estilo machadiano, este responderia a formas de "dizer o outro e de dizer outra coisa abrindo lacunas entre as reiterações do mesmo, do 'igual', por onde se insinua o distanciamento irônico da diferença" (CAMPOS, 2006, p. 224). Esse "outro" que passa pelo "mesmo", então, desarticula o que neste último há de naturalizado e dominante. Nesse sentido, ele diz respeito àquilo que, ganhando legibilidade na ficção, nos oferece visadas éticas em relação ao plano normativo dos enunciados. Lembremos, a esse respeito, do desfecho do conto machadiano, em que Mariana pede ao marido que troque o novo chapéu pelo antigo; o qual, por sua vez, talvez já não seja exatamente o mesmo que figura ao início da narrativa (assim como já não é a mesma a relação da mulher com as coerções que lhe impõe Conrado).

Expressos em imagens, frases e personagens, os múltiplos estilos da literatura se fariam não em seu apartar do mundo segundo um regime representativo, por meio do qual propõem críticas sociais. Antes, nossa aposta é a de que eles operam em negociação permanente com esse mundo, segundo um regime que se quer ético ou afetivo. Para além de perspectivas estritamente humanistas, tais estilos - suas pedagogias - se situariam entre sujeitos e objetos, humanos e não-humanos, redesenhando a um só tempo tanto os horizontes de um campo social quanto os das subjetividades: possibilidade sempre em aberto nos interstícios dos conjuntos molares. Ou para falarmos, ainda uma vez, nos termos do personagem Conrado em relação a um chapéu, "ninguém o pode trocar sem mutilação [...]. Quem sabe? Pode ser até que nem mesmo o chapéu seja complemento do homem, mas o homem, do chapéu..." (ASSIS, 2008, p. 378). 


\section{Referências}

ASSIS, Machado de. Obra completa em quatro volumes. 2. ed. Rio de Janeiro: Nova Aguilar, 2008. v. 2.

BOSI, Alfredo. Brás Cubas em três versões: estudos machadianos. 1. ed. São Paulo: Companhia das Letras, 2006.

. Machado de Assis: o enigma do olhar. 4. ed. São Paulo: WMF Martins Fontes, 2007.

CAMPOS, Haroldo de. Arte pobre, tempo de pobreza, poesia menos. In:

Metalinguagem \&t outras metas. 4. ed. São Paulo: Perspectiva, 2006. p. 221230.

DELEUZE, Gilles; GUATTARI, Félix. Kafka: por uma literatura menor. 1. ed. Belo Horizonte: Autêntica, 2014.

DURKHEIM, Émile. As regras do método sociológico. 3. ed. São Paulo: Martins Fontes, 2007.

FAORO, Raymundo. A pirâmide e o trapézio. 3. ed. Rio de Janeiro: Globo, 1988.

GLEDSON, John. O Mot de l'énigme, de Madame Craven, onze vezes: leituras femininas (e não-leituras masculinas) em "Capítulo dos chapéus", de Machado de Assis. In: Por um novo Machado de Assis. São Paulo: Companhia das Letras, 2006. p. 103-133.

KLINGER, Diana. Literatura e ética: da forma para a força. 1. ed. Rio de Janeiro: Rocco, 2014.

LATOUR, Bruno. Politiques de la nature: comment faire entrer les sciences en démocratie. 1. ed. Paris: Éditions La Découverte, 1999.

Changer de société, refaire de la sociologie. 1. ed. Paris: Éditions La Découverte, 2006.

Reagregando o social: uma introdução à teoria do ator-rede. 1. ed. Salvador; Bauru, São Paulo: Edufba; Edusc, 2012.

. Jamais fomos modernos: ensaio de antropologia simétrica. 3. ed. São Paulo: Editora 34, 2013.

SANTOS, Roberto Corrêa de. Modos de saber, modos de adoecer. 1. ed. Belo Horizonte: Editora UFMG, 1999.

. A moeda e a economia da vida mental em Machado de Assis. In:

DINIZ, Julio (Orgs.). Machado de Assis (1908-2008). Rio de Janeiro: PUC-Rio: Contraponto, 2008. p. 135-147.

SCHWARZ, Roberto. Ao vencedor as batatas. 5. ed. São Paulo: Duas Cidades; Ed. 34, 2000a.

.Um mestre na periferia do capitalismo. 4. ed. São Paulo: Ed. 34, 2000 b. 
RAFAEL MEIRE é doutor em Literatura, Cultura e Contemporaneidade pela PUC-Rio. Com pesquisas transdisciplinares sobre literatura, teoria e crítica literária, interessa-se por temas que discutem as maneiras como o campo do estético tem respondido às demandas do pensamento contemporâneo no tocante à questão do comum e das comunidades. Professor do curso de extensão "Escrever Resistências" (CCE/PUC-Rio), publicou recentemente o artigo "Alianças intensivas em 'O capitão Mendonça'", no qual, a partir do conto homônimo de Machado de Assis, discute os conceitos de estilo e mediação em perspectiva pós-humanista. (iD http://orcid.org/0000-0002-4576-0615. Email: rafael22meire@gmail.com

Recebido: 14.06.2019

Aprovado: 04.09.2019 